Ю. Я. Самохвалов ${ }^{1}$, О. И. Бурба ${ }^{2}$

${ }^{1}$ Киевский национальный университет имени Тараса Шевченко, Киев, Украина

${ }^{2}$ Украинский институт научно-технической экспертизы и информации, Киев, Украина

\title{
ОЦЕНКА ЭФФЕКТИВНОСТИ НАУЧНЫХ И НАУЧНО-ТЕХНИЧЕСКИХ ПРОЕКТОВ НА ОСНОВЕ ОБОБЩЕННОЙ ФУНКЦИИ ХАРРИНГТОНА
}

\begin{abstract}
Предметом исследований в статье являются процессы оценки научно-технического уровня научных и научнотехнических проектов путем применения бальных шкал различной длины с использованием в качестве функции обобщенного показателя аддитивной свертки. Целью статьи является разработка методического подхода к оценке эффективности научных и научно-технических проектов, согласно которому в качестве интегрального показателя используется обобщенная функция Харрингтона. Задача статьи состоит в анализе существующих подходов к оценке научнотехнического уровня научных и научно-технических проектов, методических аспектов использования обобщенного показателя эффективности и обоснование использования обобщенной функции Харрингтона. В ходе исследования использовались методы системного и сравнительного анализа, методы экспертного оценивания, математического и имитационного моделирования. Получены следующие результаты. Рассмотрена система критериев и показателей оценки, на основании которых определяется степень прогрессивности (новизны) и полезности результатов научноисследовательских и опытно-конструкторских работ. Оценка научно-технического уровня проекта осуществляется экспертным путем и основывается на получении численных значений показателей новизны, значимости для науки и практики, объективности, доказательности и точности результатов с последующим вычислением интегрального (обобщенного) показателя по конкретному проекту. При этом предложено использование обобщенной функции Харрингтона, которая позволяет избежать использования аддитивного интегрального показателя при оценке научно-технического качества проектов. Выводы. Рассмотрено применение обобщенной функции Харрингтона в качестве интегрального показателя эффективности научных и научно-технических проектов. Это дает возможность, во-первых, избежать аддитивного интегрального показателя качества научных и научно-технических проектов Во-вторых, для каждого показателя эффективности выбирать такую шкалу оценки, максимально согласована с объективными отношениями, которым подчинен соответствующий показатель. В-третьих, использование шкалы Харрингтона позволяет интерпретировать обобщенный показатель эффективности научных исследования модальными категориями термина "желательно".
\end{abstract}

Ключевы е слов а: научно-техническая экспертиза, эффективность научно-технических проектов, обобщенная функция Харрингтона, шкала оценивания.

\section{Введение}

Одним из приоритетных направлений на современном этапе развития общества является разработка и реализация научно-технических проектов, направленных на создание наукоемкой продукции с дополнительным экономическим эффектом. В связи с этим важное значение приобретает определение эффективности научных исследований, что является одним из существенных рычагов ускорения научно-технического прогресса, концентрации научного потенциала на наиболее важных направлениях развития страны и снижения распыления материальных и финансовых ресурсов. Модель финансирования научной сферы в Украине в значительной степени опирается на средства государственного бюджета. В связи с этим особое значение приобретает всесторонняя государственная научная и научно-техническая экспертиза (ННТЭ) научно-технического уровня научных исследований, кросс-секторальных инновационных проектов и других государственных программ, планируемых к выполнению за бюджетные средства или в рамках государственного заказа.

Постановка проблемы в общем виде. Задача определения эффективности научных исследований является сложной многокритериальной задачей, решаемой в условиях неполноты или неопределенности исходной информации [1]. В качестве критериев эффективности научных и научно-технических проектов, как правило, выступают их новизна, значи- мость для науки и практики, объективность, доказательность и точность [2]. В свою очередь эти критерии декомпозируются на более детальные показатели научно-технического уровня проектов.

Для решения многокритериальных задач широко используются различные методы построения обобщенного показателя. Учитывая разнообразие тематик этих проектов [3] в качестве частных показателей выступают различные технические, технологические, социально-экономические и эстетические показатели. А так как эти показатели имеют различную физическую природу и, следовательно, различную размерность, важным моментом формирования обобщенного показателя является приведение частных показателей к безразмерному виду.

Такое преобразование, как правило, осуществляется с помощью соответствующих нормирующих шкал, причем, для каждого показателя вводится своя шкала. Выбрать такую шкалу достаточно трудно, так как она должна быть однотипной для всех частных показателей, иначе их нельзя будет сравнить. Кроме этого такой выбор должен быть обоснован, т.е. шкала измерения должна максимально быть согласована с объективными отношениями, которым подчинен соответствующий показатель.

Анализ последних исследований и публикаций. Практика проведения ННТЭ как в Украине, так и за рубежом позволяет отметить следующие подходы к использованию нормирующих шкал. Так при проведении экспертизы научных и научно-технических проек- 
тов в Министерстве образования и науки Украины, а также в республике Беларусь частные показатели, как правило, оцениваются по бальным шкалам различной длины [4-5]. В Европейском Союзе показатели научнотехнического уровня проектов, в рамках международной программы Горизонт-2020, оцениваются по единственной 5-ти бальной шкале [6].

В работах [7-11] рассмотрены методические подходы к оцениванию научного и научно-технического уровня НИР, в которых также используется метод балльных оценок с различными шкалами. Так, в [7-9] оценка научной и научно-технической результативности НИР производится с помощью системы взвешенных балльных оценок в разных интервалах в диапазоне от 0,1 до 1 . В $[10,11]$ предлагается использовать шкалы от 1 до 10. Кроме этого для фундаментальных НИР рассчитывается только коэффициент научной результативности, а для поисковых работ также и коэффициент научно-технической результативности. Оценки коэффициентов задаются экспертами. Оценка научно-технической результативности прикладных НИР производится на основе сопоставления достигнутых в результате выполнения НИР технических параметров с базовыми. Общий коэффициент научнотехнической результативности определяется в виде свертки с учетом весовых коэффициентов показателей.

Таким образом, при оценивании научно-технического уровня научных и научно-технических проектов в основном применяются линейные бальные шкалы различной длины, а в качестве функции обобщенного показателя используется аддитивная свертка. Это положение позволяет сделать следующие критические замечания. Во-первых, так как бальные шкалы различной длины имеют различную чувствительность, следовательно, имеют различную точность измерения, поэтому оценки по таким шкалам нельзя сравнивать, а следовательно и суммировать. Во-вторых, использование аддитивного обобщенного показателя не совсем правомерно, так как линейная свертка допускает взаимную компенсацию значений частных показателей. В-третьих, поскольку значения показателей научно-технического уровня проектов представляют собой оценки экспертов, то, согласно закона Вебера-Фехнера [12], психологическая оценка какого-либо показателя нелинейно связана с его величиной. Поэтому нормирующие преобразования объективно должны быть нелинейными, что обуславливает применение нелинейных шкал.

Учитывая вышесказанное, в качестве интегрального показателя эффективности научных исследований предлагается использовать обобщенную функцию желательности Харрингтона, что позволит устранить отмеченные недостатки. Это положение определяет цель и основное содержание данной статьи.

\section{Изложение основного материала}

Критерии и показатели эффективности. В статье рассматривается прогнозная оценка научных и научно-технических проектов, которая выполняется на стадии отбора программ фундаментальных и прикладных исследований, научно-технических программ и их заданий, а также отдельных инновационных проектов.
При этом под критериями оценки будем понимать признаки, на основании которых определяется степень прогрессивности (новизны) и полезности результатов научно-исследовательских и опытно-конструкторских работ. Результаты научных и научно-технических проектов оцениваются по критериям научно-технической и социальной эффективности.

В качестве критериев научно-технической эффективности, как правило, выступает новизна, значимость для науки и практики, объективность, доказательность и точность результатов $[2,4,5]$.

Критерий новизны - наличие в результатах научной деятельности новых научных знаний (новой научной информации), которые могут характеризоваться значениями в пределах от уже известного до абсолютной новизны. Высшая степень новизны (абсолютная новизна, принципиально новая научная информация) соответствует в фундаментальных исследованиях открытиям, подтвержденным общественным признанием в форме экспертных заключений высококвалифицированных ученых в соответствующих областях знаний, а в прикладных исследованиях - изобретениям, промышленным образцам, полезным моделям, товарным знакам, сортам растений и другим объектам, на которые получены патенты. Все остальные степени (уровни) новизны определяются путем соотнесения полученных значений с абсолютной новизной и выражаются с помощью конкретных систем показателей.

Критерий значимости для науки и практики масштабы влияния результатов научных исследований на науку, экономику, социальную сферу, экологию. Масштабы влияния характеризуются:

в фундаментальных исследованиях - значениями в пределах от распространения уже известных знаний и передового опыта до коренных преобразований в науке, технике, экономике, социальной и иных сферах;

в прикладных исследованиях - от использования на отдельном предприятии до применения в масштабе всего народного хозяйства;

в инновационной сфере - от реализации отдельных изделий или мелких партий на местном рынке до выхода на мировой рынок.

Критерий объективности - степень обоснованности результата научного исследования, которая может изменяться в пределах от несоответствия до полного соответствия оценки результату. Степень объективности может выявляться посредством учета квалификации и компетентности разработчиков и экспертов и по формам признания результатов.

Критерий доказательности - характер используемой информации, способы ее получения и обработки (использование научной литературы, опыта, экспериментов, испытаний, математических методов). Степень доказательности результатов может изменяться в пределах от неопределенности до возможности воспроизведения и применения на практике. Степень доказательности результатов определяется экспертным путем.

Критерий точности - соответствие модели (образца) стандартам (техническим условиям, техниче- 
скому заданию, основным показателям бизнесплана), которое может характеризоваться от несоответствия до полного соответствия. По критерию точности классифицируют, как правило, результаты прикладных исследований при создании действующих моделей и образцов новой техники и технологий, а также результаты исследований, включенных в инновационный процесс.

Степень соответствия критериям выражается через значения конкретных показателей научнотехнического уровня. Показатели могут быть количественными (количество изобретений, патентов, лицензий, публикаций в наукометрических базах и т.д.) и качественными (принципиально новая информация, соответствие мировому научно-техническому уровню и т.д.). Качественные показатели могут также быть выражены количественно с использованием условных единиц (баллов, коэффициентов и других). Состав применяемых показателей определяется с учетом отрасли науки (естественные, технические и общественные науки) и вида научных исследований (фундаментальные, прикладные, инновационные разработки).

В [5] приведены примерные перечни результатов научной деятельности, показателей и признаков критериев новизны, значимости для науки и практики, объективности, доказательности и точности этих результатов в зависимости от сфер и видов научной деятельности. Причем для каждого критерия используется единая 5-ти бальная система показателей. Эти перечни могут выступать в качестве базовых при оценке результатов научных исследований в различных отраслях науки и при необходимости могут быть уточнены, дополнены и конкретизированы в зависимости от сфер и видов научной деятельности различных организаций.

Причем, состав показателей, характеризующих научно-технический уровень научных, научнотехнических и инновационных разработок, имеющих выраженный прикладной характер, определяется с учётом вида и назначения оцениваемых систем, конкретных целей и задач их функционирования, особенностей их разработки, изготовления и использования. Под социальной эффективностью понимается достижение социальных и экологических результатов научных, научно-технических и инновационных разработок. Эти результаты рассматриваются как источники косвенных (дополнительных) эффектов и учитываются при принятии решений о реализации и (или) государственной поддержке программ и инновационных проектов.

Экспертная оценка социальной эффективности НТП и инновационных проектов может быть двух видов: оценка социально-целевой направленности и оценка социальных последствий программы (инновационного проекта). В первом случае социальные оценки входят в состав целей НТП и инновационных проектов, во втором - как вторичные, латентные последствия, возникающие в результате их реализации.

Оценка социальной эффективности НТП и инновационных проектов отражает вклад результатов разработок в улучшение социальной среды и, в конечном счете, в повышение качества жизни людей и характеризуется показателями: уровня и образа жизни; здоровья и продолжительности жизни [2]. Там же приведены показатели оценки экологических результатов НТП и инновационных проектов. К таким показателям относятся:

выбросы (сбросы) загрязняющих веществ в окружающую среду, размещение отходов в окружающей среде, воздействие на земельные ресурсы, лесные ресурсы, животный мир;

безотходность производства за счет замкнутого технологического цикла переработки ресурсов;

приближение к биосферосовместимому типу технологий.

Таким образом, систему критериев оценки эффективности научных (фундаментальных) исследований, научно-технических (прикладных) и инновационных разработок можно представить следующей иерархической структурой (рис. 1). На рис. 2 приведен пример показателей оценки научнотехнической эффективности результатов прикладных исследований.

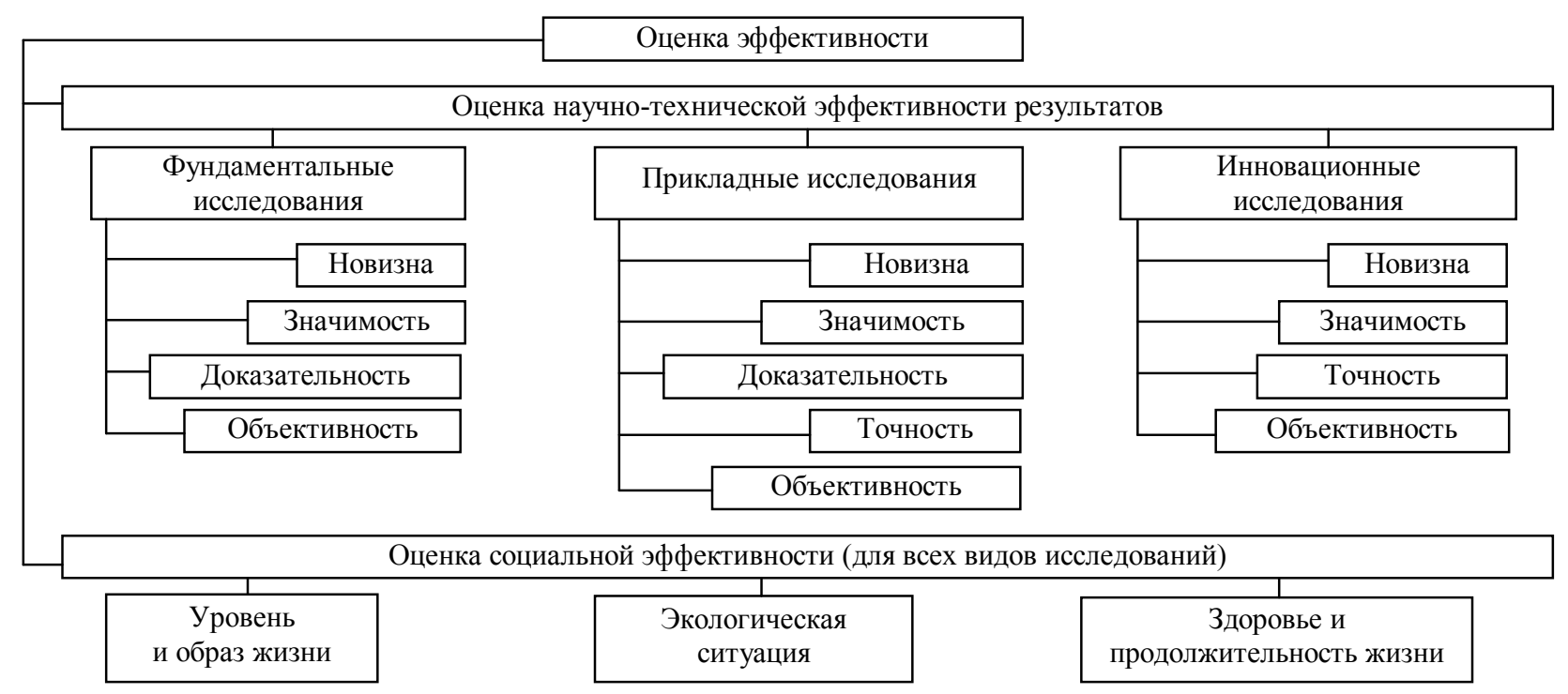

Рис. 1. Структура системы критериев оценки эффективности исследований 


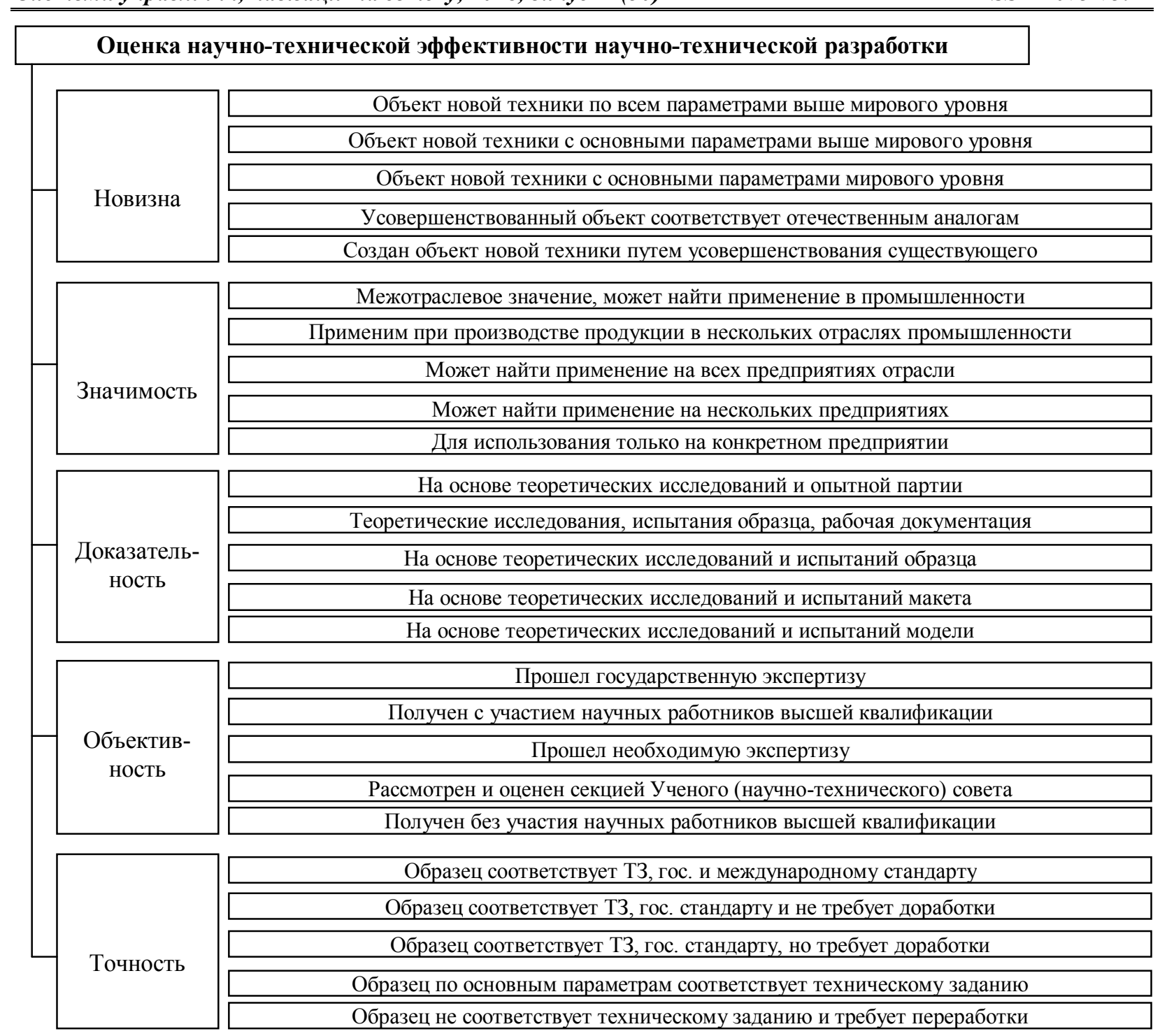

Рис. 2. Показатели оценки научно-технической эффективности научных исследований

И, наконец, показателями оценка социальной эффективности научных исследований для всех критериев являются: низкий, средний, высокий.

Оценка проектов. Основной целью оценки эффективности научных, научно-технических и инновационных разработок (проектов) является определение их научно-технического уровня и конкурентноспособности, соответствия принципам наилучших доступных технологий, достижимости поставленных научнотехнических параметров, соответствия расходов и сроков разработки рыночным условиям [2]. Оценка научно-технического уровня проекта осуществляется экспертным путем и основывается на получении численных значений показателей новизны, значимости для науки и практики, объективности, доказательности и точности результатов и вычислении интегрального (обобщенного) показателя по конкретному проекту.

Одним из наиболее удобных способов построения интегрального показателя является обобщенная функция желательности Харрингтона [13]. В основе построения этой функции лежит преобразование натуральных значений частных показателей различной физической природы и размерности в единую безразмерную шкалу желательности (предпочтительности).
Шкала желательности Харрингтона является универсальной психофизической вербально-числовой шкалой, которая применяется преимущественно в случаях, когда оценки носят субъективный характер, в частности, при экспертном оценивании и позволяет формализовать имеющуюся у эксперта систему предпочтений. Эта шкала задается функцией желательности (кривой желательности) Харрингтона, которая устанавливает соответствие между натуральными значениями показателей в физических шкалах и психофизическими параметрами - субъективными лингвистическими оценками «желательности» этих значений для функции, объекта, системы или человека. В табл. 1 приведена связь между количественными значениями безразмерной шкалы и психологическим восприятием человека. При этом нижняя граница каждого интервала значений включается в соответствующий интервал. Практически часто ограничиваются тремя градациями шкалы Харрингтона, отвечающим лингвистическим категориям «низкая», «удовлетворительная» (средняя), «высокая» (хорошая). В этом случае области, соответствующие уровням «низкая», «удовлетворительная» и «высокая» характеризуются интервалами $(0,00-0,37)$, $(0,37-0,69)$ и $(0,69-1,00)$ соответственно. 
Таблица 1 - Вербально-числовая шкала Харрингтона

\begin{tabular}{|c|c|}
\hline $\begin{array}{c}\text { Лингвистическая оценка } \\
\text { желательности }\end{array}$ & $\begin{array}{c}\text { Интервалы значений } \\
\text { функции желательности }\end{array}$ \\
\hline Очень высокая & $0,8-1,0$ \\
\hline Высокая & $0,63-0,8$ \\
\hline Удовлетворительная & $0,37-0,63$ \\
\hline Низкая & $0,2-0,37$ \\
\hline Очень низкая & $0,0-0,2$ \\
\hline
\end{tabular}

Первоначальным этапом построения обобщенной функции желательности Харрингтона является задание границ допустимых значений $(y)$ для всех частных показателей. Такие границы могут быть установлены, например, на основе инструктивных документов, стандартов, норм и правил или экспертным путем, если такие данные отсутствуют. При этом ограничения могут быть односторонние или двусторонние. Если улучшение общей характеристики происходит только при однонаправленном изменении показателя (уменьшении или увеличении) - ограничение носит односторонний характер в виде $y_{i} \leq y_{\max }$ или $y_{i} \geq y_{\min }$. Если изменение показателя вероятно в обе стороны от оптимального значения, то ограничение носит двусторонний характер $y_{\min } \leq y_{i} \leq y_{\max }$.

При одностороннем ограничении значению желательности 0,37 соответствует $y_{\min }$ или $y_{\max }$ (задан нижний или верхний предел соответственно), при двустороннем ограничении - и $y_{\min }$ и $y_{\max }$. Примером показателя, для которого устанавливается одностороннее ограничение, является время реакции - чем меньше время реакции, тем значение показателя желательности больше, а примером показателя с двусторонним ограничением, является величина артериального давления - ее оптимальные значения лежат в определенном диапазоне, а повышение или понижение значений относительно оптимума приводят к снижению показателя желательности.

Для одностороннего ограничения в случае «позитивных» показателей, для которых характерна монотонная и возрастающая зависимость желательности от их числовых значений, функция Харрингтона имеет следующий сигмоидальный вид (рис. 3).

Эта функция задается формулой:

$$
d=\exp \left(-\exp \left(-y^{\prime}\right)\right)
$$

где $y^{\prime}$ - шкала кодированных значений частных показателей $y, d$ - шкала желательности.

Из рис. 3 видно, что функция желательности на участке «удовлетворительно» близка к линейной, а в областях желательностей близких к 0 и 1 проявляется ее нелинейность. То есть, ее чувствительность в этих областях существенно ниже, чем в средней зоне, что вполне согласуется с законом ВебераФехнера. Интервал от -2 до 5 на шкале кодированных значений частных показателей является промежутком эффективных значений [14]. Нормирование количественных значений частных показателей осуществляется следующим образом. Каждый показатель $y$ пересчитывается в числовые отметки в диапазоне от -2 до +5 . При этом если «наибольшему» из всех значений частных показателей «присвоить» отметку «+5», а «наименьшему» - «-2», то все остальные расположатся между ними, образуя масштабируемую последовательность значений $y_{i}^{\prime}$.

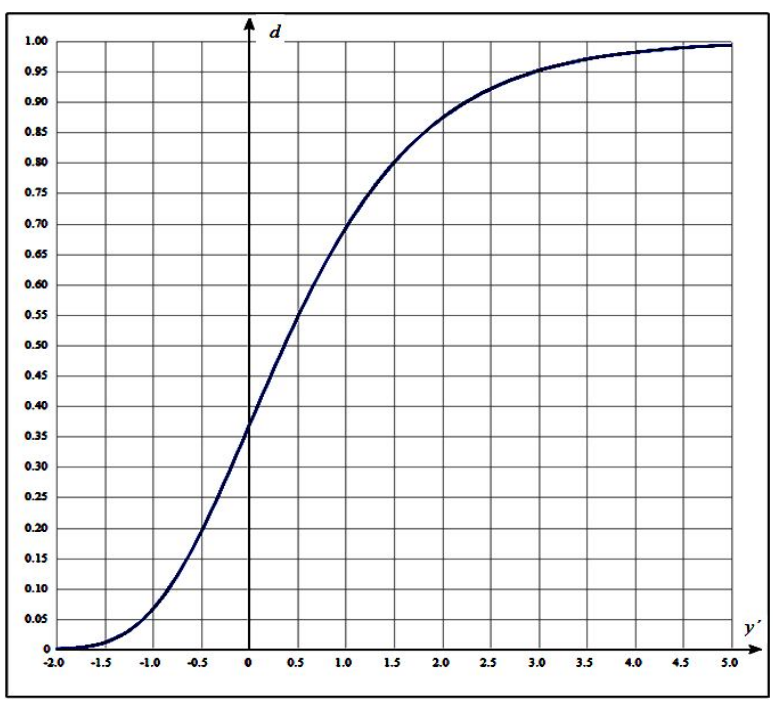

Рис. 3. График функции желательности Харрингтона с односторонним ограничением

Такое преобразование можно осуществить, например, по следующей формуле:

$$
y^{\prime}=-2+7 \cdot\left(y-y_{\min }\right) /\left(y_{\max }-y_{\min }\right),
$$

где $y_{\min }$ и $y_{\max }-$ нижняя и верхняя границы области изменения показателя $y$.

При этом при переводе кодированных значений $y_{i}^{\prime}$ частных показателей в частные желательности $d_{i}$, значение $d_{i}=0$ будет соответствовать абсолютно неприемлемому уровню данного показателя, значение $d_{i}=1$ - самому лучшему его значению, значение $d_{i}=0.37$ обычно соответствует границе допустимых значений. В табл. 2 приведены табулированные значения функции желательности.

Таблица 2 -Значения функции желательности

\begin{tabular}{|r|r|r|r|r|r|}
\hline$y_{i}^{\prime}$ & $-2,0$ & $-1,5$ & -1 & $-0,5$ & 0 \\
\hline$d_{i}$ & 0,001 & 0,011 & 0,066 & 0,192 & 0,368 \\
\hline$y_{i}^{\prime}$ & 0,5 & 1,0 & 1,5 & 2,0 & 2,5 \\
\hline$d_{i}$ & 0,545 & 0,692 & 0,800 & 0,873 & 0,921 \\
\hline$y_{i}^{\prime}$ & 3,0 & 3,5 & 4,0 & 4,5 & 5,0 \\
\hline$d_{i}$ & 0,951 & 0,970 & 0,982 & 0,989 & 0,993 \\
\hline
\end{tabular}

При двустороннем ограничении функция желательности задается формулой:

$$
d=\exp \left(-\left|y^{\prime}\right|^{n}\right),
$$

где $y^{\prime}$ - кодированное значение частного параметра $y, n$ - положительное число не обязательно целое. 
Чтобы функция (3) была построена по месту расположения левой и правой границ необходимо значения $y^{\prime}$ вычислять по формуле:

$$
y^{\prime}=\left(2 y-y_{\max }-y_{\min }\right) /\left(y_{\max }-y_{\min }\right) .
$$

На рис. 4 представлен график функции желательности с двусторонним ограничением для $n=2$.

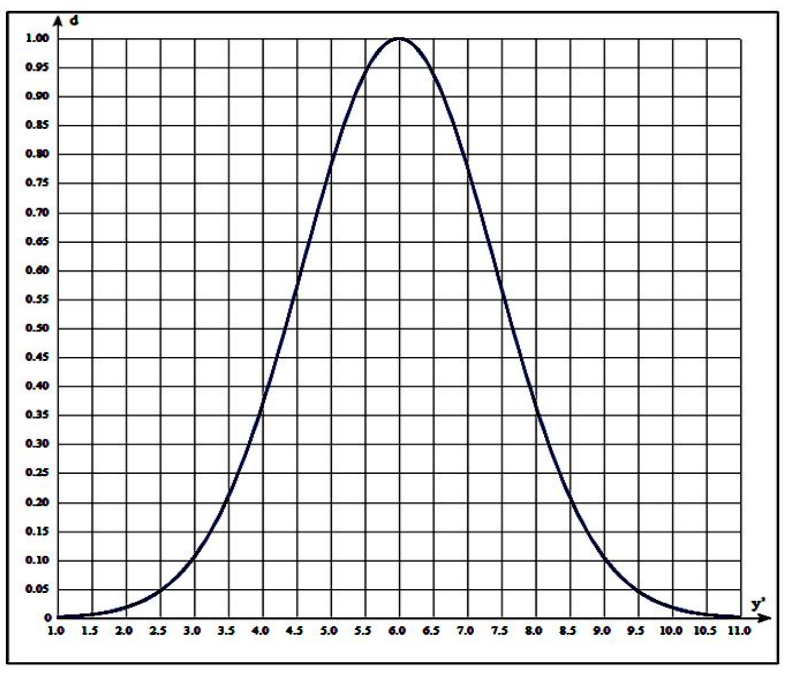

Рис. 4. График функции желательности с двусторонним ограничением

В общем, показатель $n$ можно вычислить по формуле $\quad n=(\ln \ln (1 / d)) /\left(\ln \left|y^{\prime}\right|\right)$, если задать некоторому значению $y$ значение $d$ (предпочтительно в интервале $0.6<d<0.9$, обычно $d=0.7$ ). Задавая при помощи контрольной точки крутизну кривой желательности, можно учесть особую важность отдельных показателей. Для этих показателей $n$ будет большим, и незначительное их изменение вблизи границ будет приводить к резкому изменению желательности. Показатель степени $n$ определяет наклон кривой, и когда $n$ становится большим, кривая приближается к своей предельной форме: $d=0$ вне заданных пределов и $d=1$ между этими пределами.

После вычисления всех частных желательностей $d_{i}$ осуществляется их свертка в обобщенный критерий $D$ - обобщенная функция желательности. В случае отсутствия весовых коэффициентов эта функция задается формулой

$$
D=\sqrt[n]{\prod_{i=1}^{n} d_{i}}
$$

Для обобщенного показателя используется та же шкала предпочтительности (табл. 1), что и для частных показателей. Если устанавливаются весовые коэффициенты частных критериев, то обобщенный критерий рассчитывается как взвешенное среднее геометрическое:

$$
D=\prod_{i=1}^{n} d_{i}^{\alpha}{ }_{i}
$$

где $\alpha_{i}-$ вес частной желательности $d_{i}$, причем $\sum_{i=1}^{n} \alpha_{i}=1[15]$.
Обобщенная функция желательности весьма чувствительна к малым значениям частных желательностей и превращается в ноль, если хотя бы одно из отдельных свойств получает нулевую оценку. В то же время она равна единице, когда все частные желательности также равны единице. Когда столь жесткие свойства обобщенного критерия являются неприемлемыми, тогда нужно использовать другие способы обобщения, например, аддитивную свертку.

Таким образом, процесс оценки научнотехнического уровня проектов на основе обобщенной функции желательности Харрингтона состоит из следующих этапов:

1. Определение перечня частных критериев и показателей оценки.

2. Установление границы допустимых значений для всех показателей.

3. Вычисление частных желательностей.

4. Вычисление обобщенной функции желательности.

Поскольку примеры более доходчивы, чем общие рассуждения, рассмотрим один из них.

На примере оценивания заявок на участие в конкурсе МОН Украины на финансирование научно-технических разработок за государственным заказом рассмотрим существующий и предлагаемый подходы.

Согласно требованиям к научно-техническим разработкам за государственным заказом в качестве показателей оценивания используются такие характеристики [4]: соответствие планируемого научнотехнического результата приоритетным государственным потребностям; практическая ценность планируемых научно-технических результатов; научная новизна планируемых результатов; уровень научнотехнической продукции; степень готовности результатов к внедрению; наличие научного задела и опыта у коллектива авторов; степень детализации календарного плана работ; реалистичность путей и способов внедрения результатов работы в практику; обоснованность финансовых показателей проекта. В табл. 3 приведена карточка экспертного оценивания заявок. В табл. 4 приведены результаты экспертного оценивания трех заявок $\mathrm{Z}_{1}, \mathrm{Z}_{2}$ и $\mathrm{Z}_{3}$.

В рамках существующего подхода ранжирование заявок осуществляется на основе их общего балла, который вычисляется как сумма баллов частных показателей. Исходя из этого, имеем $\mathrm{Z}_{3} \succ \mathrm{Z}_{1} \succ \mathrm{Z}_{2}$, где $\succ-$ символ предпочтения.

Теперь оценим эти заявки с помощью обобщенной функции Харрингтона. При этом для “чистоты эксперимента” будем использовать те же оценки частных показателей. В табл. 5 приведены оценки заявок и их границы $y_{\min }, y_{\max }$.

В табл. 6 приведены кодированные значения частных показателей заявок $Z_{1}, Z_{2}$ и $Z_{3}$, полученные по формуле (2). Причем значения всех показателей имеют односторонние ограничения. В табл. 7, согласно (1) и (6), приведены значения $d_{i}$ частных желательностей и значения $D$ обобщенной функции желательности для каждой заявки с учетом равных весов частных показателей заявок. 


\section{Таблича 3 - Карточка экспертного оценивания заявок}

\begin{tabular}{|c|c|c|}
\hline \multicolumn{2}{|r|}{$\begin{array}{c}\text { Карточка экспертного оценивания заявки } \\
\text { на участие в конкурсе научно-технических разработок за государственным заказом }\end{array}$} & $\begin{array}{l}\text { Оценка } \\
\text { (баллы) }\end{array}$ \\
\hline 1 & \multicolumn{2}{|l|}{ Соответствие запланированного научно-технического (прикладного) результата приоритетным гос. потребностям } \\
\hline 1.1 & Соответствует полностью. & 5 \\
\hline 1.2 & Соответствует частично. & 3 \\
\hline 1.3 & Не соответствует. & 0 \\
\hline 2 & \multicolumn{2}{|l|}{ Практическая ценность планируемых научно-технических результатов } \\
\hline 2.1 & $\begin{array}{l}\text { Результаты НТР имеют межотраслевое значение, могут найти применение в промышленности, сельском хозяйст- } \\
\text { ве, на транспорте и в других отраслях народного хозяйства }\end{array}$ & 7 \\
\hline 2.2 & Результаты НТР применимы при производстве продукции в нескольких отраслях промышленности & 5 \\
\hline 2.3 & Результаты НТР могут найти применение на всех предприятиях отрасли & 3 \\
\hline 2.4 & Результаты НТР могут найти применение на нескольких предприятиях, использующих однотипное оборудование & 2 \\
\hline 2.5 & $\begin{array}{l}\text { Результаты НТР предназначены для использования только на конкретном предприятии (без тиражирования на } \\
\text { другие предприятия) }\end{array}$ & 1 \\
\hline 2.6 & Результаты НТР не имеют практической цености для экономики и общества. & 0 \\
\hline 3 & \multicolumn{2}{|l|}{ Научная новизна, наличие новых технических/технологических решений } \\
\hline 3.1 & Создан уникальный объект новой техники (способ, технол. процесс), получены принципиально новые результаты & 6 \\
\hline 3.2 & Некоторые общие закономерности, методы, способы, позволяющие создать принципиально новую продукцию & 4 \\
\hline 3.3 & $\begin{array}{l}\text { Положительное решение на основе простых обобщений, анализа связей факторов, распространение известных } \\
\text { принципов на новые объекты }\end{array}$ & 2 \\
\hline 3.4 & Описание отдельных факторов, распространение ранее полученных результатов & 0 \\
\hline 4 & \multicolumn{2}{|l|}{ Оценка уровня научно-технической продукции, которая ожидается в результате выполнения НТР } \\
\hline 4.1 & Объект новой техники по всем параметрами выше мирового уровня & 8 \\
\hline 4.2 & Объект новой техники с сновними параметрами выше мирового уровня & 7 \\
\hline 4.3 & Объект новой техники с сновними параметрами мирового уровня & 5 \\
\hline 4.4 & Усовершенствованный объект соответствует отечественным аналогам & 3 \\
\hline 4.5 & $\begin{array}{l}\text { Создан объект новой техники путем усовершенствования существующего на основании известных решений. } \\
\text { Аналогичная продукция существует. }\end{array}$ & 1 \\
\hline 4.6 & Результаты НТР по основным параметрам уступают аналогам. & 0 \\
\hline 5 & \multicolumn{2}{|l|}{ Степень готовности результатов к внедрению } \\
\hline 5.1 & Результат предполагает создание, изготовление опытных образцов продукции & 9 \\
\hline 5.2 & $\begin{array}{l}\text { Результат предполагает создание и испытание опытного образца изделия, материала, технологии, изготовленного } \\
\text { по рабочей документации }\end{array}$ & 7 \\
\hline 5.3 & Результат предполагает разработку и испытания экспериментального образца изделия, материала, технологии & 5 \\
\hline 5.4 & Результат предполагает разработку макета изделия, материала, технологии & 3 \\
\hline 5.5 & Результат предполагает создание экспериментальной модели изделия, материала, технологии & 2 \\
\hline 5.6 & Результат предполагает только теоретические исследования & 0 \\
\hline 6 & \multicolumn{2}{|l|}{ Наличие научного задела и опыта у коллектива авторов за тематикой НТР } \\
\hline 6.1 & Авторы имеют значительный научный потенциал и опыт по тематике НТР & 4 \\
\hline 6.2 & Авторы имеют определенный (незначительный) задел и опыт по определенной тематике. & 2 \\
\hline 6.3 & Авторы не имеют задела и опыта по тематике НТР. & 0 \\
\hline 7 & \multicolumn{2}{|l|}{ Степень детализации календарного плана работ. } \\
\hline 7.1 & $\begin{array}{l}\text { Содержание этапов выполнения работ календарного плана детализированное и соответствует требованиям нор- } \\
\text { мативов и стандартов в соответствующей сфере. }\end{array}$ & 5 \\
\hline 7.2 & $\begin{array}{l}\text { Содержание этапов выполнения работ частично детализированно, но не определена научно-техническая продук- } \\
\text { ция, которую получит заказчик по результатам каждого из этапов выполнения работ кроме научного отчета. }\end{array}$ & 3 \\
\hline 7.3 & Содержание этапов работ и состав научно-технической продукции не детализировано, указано формально. & 1 \\
\hline 7.4 & Календарный план отсутствует. & 0 \\
\hline 8 & \multicolumn{2}{|l|}{ Оценка реалистичности путей и способов внедрения результатов работы в практику результатов выполнения НТР } \\
\hline 8.1 & Пути и способы внедрения в практику научно-технической продукции подробно описаны и реалистичны. & 5 \\
\hline 8.2 & Пути и способы внедрения научно-технической продукции описаны не детально. & 3 \\
\hline 8.3 & Приведенные в заявке пути и способы внедрения научно-технической продукции не описаны или нереальны. & 0 \\
\hline 9 & \multicolumn{2}{|l|}{ Обоснованность финансовых показателей проекта } \\
\hline 9.1 & Затраты на реализацию проекта обоснованы & 4 \\
\hline 9.2 & Затраты на реализацию проекта обоснованы частично & 2 \\
\hline 9.3 & Затраты на реализацию проекта не обоснованы & 0 \\
\hline
\end{tabular}

\section{Таблица 4 - Результаты экспертного оценивания}

\begin{tabular}{|c|c|c|c|c|}
\hline \multirow{2}{*}{ № } & \multirow{2}{*}{ Показатель } & \multicolumn{3}{|c|}{ Заявка } \\
\hline & & $\overline{Z_{1}}$ & $\mathbf{Z}_{2}$ & $\mathbf{Z}_{3}$ \\
\hline 1 & $\begin{array}{l}\text { Соответствие планируемого научно-технического результата приоритетным государствен- } \\
\text { ным потребностям }\end{array}$ & 5 & 3 & 5 \\
\hline 2 & Практическая ценность планируемых научно-технических результатов & 7 & 2 & 7 \\
\hline 3 & Научная новизна планируемых результатов & 4 & 4 & 6 \\
\hline 4 & Уровень научно-технической продукции & 6 & 7 & 8 \\
\hline 5 & Степень готовности результатов к внедрению & 7 & 3 & 5 \\
\hline 6 & Наличие научного задела и опыта у коллектива авторов & 4 & 2 & 4 \\
\hline 7 & Степень детализации календарного плана работ & 3 & 5 & 3 \\
\hline 8 & Реалистичность путей и способов внедрения результатов работы & 3 & 0 & 5 \\
\hline \multirow[t]{2}{*}{9} & Обоснованность финансовых показателей проекта & 4 & 2 & 2 \\
\hline & Общий балл & 43 & 28 & 45 \\
\hline
\end{tabular}


Таблица 5 - Оценки заявок и их границы

\begin{tabular}{|c|c|c|c|c|c|c|}
\hline \multirow{2}{*}{ № } & \multirow{2}{*}{ Показатель } & \multicolumn{3}{|c|}{ Заявка } & \multirow[b]{2}{*}{$y_{\min }$} & \multirow{2}{*}{$y_{\max }$} \\
\hline & & $\mathrm{Z}_{1}$ & $\mathbf{Z}_{2}$ & $\mathbf{Z}_{3}$ & & \\
\hline 1 & Соответствие планируемого научно-технического результата приоритетным гос. потребностям & 5 & 3 & 5 & 0 & 5 \\
\hline 2 & Практическая ценность планируемых научно-технических результатов & 7 & 2 & 7 & 0 & 7 \\
\hline 3 & Научная новизна планируемых результатов & 4 & 4 & 6 & 0 & 6 \\
\hline 4 & Уровень научно-технической продукции & 6 & 7 & 8 & 0 & 8 \\
\hline 5 & Степень готовности результатов к внедрению & 7 & 3 & 5 & 0 & 9 \\
\hline 6 & Наличие научного задела и опыта у коллектива авторов & 4 & 2 & 4 & 0 & 4 \\
\hline 7 & Степень детализации календарного плана работ & 3 & 5 & 3 & 0 & 5 \\
\hline 8 & Реалистичность путей и способов внедрения результатов работы в практику & 3 & 0 & 5 & 0 & 5 \\
\hline 9 & Обоснованность финансовых показателей проекта & 4 & 2 & 2 & 0 & 4 \\
\hline
\end{tabular}

Таблица 6 - Кодированные значения частных показателей заявок

\begin{tabular}{|c|c|c|c|c|c|c|c|c|c|}
\hline Заявка & $y_{1}^{\prime}$ & $y_{2}^{\prime}$ & $y_{3}^{\prime}$ & $y_{4}^{\prime}$ & $y_{5}^{\prime}$ & $y_{6}^{\prime}$ & $y^{\prime} 7$ & $y_{8}^{\prime}$ & $y_{9}^{\prime}$ \\
\hline $\mathrm{Z}_{1}$ & 5 & 5 & 2,67 & 3,25 & 3,447 & 5 & 2,2 & 2,2 & 5 \\
\hline $\mathrm{Z}_{2}$ & 2,2 & 0 & 2,67 & 4,125 & 0,337 & 1,5 & 5 & -2 & 1,5 \\
\hline $\mathbf{Z}_{3}$ & 5 & 5 & 5 & 5 & 1,89 & 5 & 2,2 & 5 & 1,5 \\
\hline
\end{tabular}

Таблица 7 - Значения частных желательностей и обобщенной функции Харрингтона

\begin{tabular}{|c|c|c|c|c|c|c|c|c|c|c|}
\hline Заявка & $d_{1}$ & $d_{2}$ & $d_{3}$ & $d_{4}$ & $d_{5}$ & $d_{6}$ & $d_{7}$ & $d_{8}$ & $d_{9}$ & D \\
\hline $\mathrm{Z}_{1}$ & 0,99 & 0,99 & 0,93 & 0,96 & 0,97 & 0,99 & 0,89 & 0,89 & 0,99 & 0,958 \\
\hline $\mathbf{Z}_{2}$ & 0,89 & 0,37 & 0,93 & 0,98 & 0,49 & 0,8 & 0,99 & 0,0 & 0,8 & 0,0 \\
\hline $\mathbf{Z}_{3}$ & 0,99 & 0,99 & 0,99 & 0,99 & 0,86 & 0,99 & 0,89 & 0,99 & 0,8 & 0,943 \\
\hline
\end{tabular}

Имеем $\mathrm{Z}_{1} \succ \mathrm{Z}_{3} \succ \mathrm{Z}_{2}$. Изменение порядка доминирования заявок произошло из-за особенностей существующего подхода, которые привели к искажению результата ранжирования. Эти особенности, как было отмечено, заключаются в том, что оценки частных показателей полученные по шкалам различной длины суммировать нельзя, так как линейная свертка допускает взаимную компенсацию значений частных показателей - низкие оценки по одним показателем могут быть компенсированы высокими оценками по другим.

\section{Выводы}

Рассмотрено применение обобщенной функции Харрингтона в качестве интегрального показателя эффективности научных и научно-технических проектов. Это дает возможность, во-первых, уйти от аддитивного интегрального показателя качества научных и научно-технических проектов Во-вторых, для каждого показателя эффективности выбирать такую шкалу оценки, которая максимально согласована с объективными отношениями, которым подчинен соответствующий показатель. В-третьих, использование шкалы Харрингтона позволяет интерпретировать обобщенный показатель эффективности научных исследование модальными категориями термина “желательно”.

Рассмотренные методические аспекты могут быть использованы при планировании и проведении оценки эффективности выполнения государственных программ научных исследований; научнотехнических программ и их отдельных заданий; мероприятий по научному обеспечению государственных программ и инновационных проектов.

\section{СПИСОК ЛІТЕРАТУРИ}

1. Деменков, Н. П. Программное обеспечение для оценки эффективности разнотипных научно-исследовательских работ / Н.П. Деменков // Инженерный вестник МГТУ им. Н.Э. Баумана. - 2013. - № 11. - С. 1011-1024.

2. Методические рекомендации по оценке эффективности научных, научно-технических и инновационных разработок и их внедрения / Постановление Государственного комитета по науке и технологиям Республики Беларусь от 20 апреля 2017 г. № 9 // Электронный pecypc. Режим доступа:http:/gostsnip.su/document/stb_1078_97_otsenka_nauchno_tehnicheskogo_urovnya_i_konkurentosposobno

3. Закон Украины "О приоритетных направлениях развития науки и техники" / Электронный ресурс. Режим доступа: http://zakon2.rada.gov.ua/laws/show/2623-14

4. Приказ Министерства образования и науки Украины от 09.02.2017 № 192 / Электронный ресурс. Режим доступа http://zakon3.rada.gov.ua/laws/show/z0339-17

5. Постановление Национальной академии наук Беларуси и Государственного комитета по науке и технологиям Республики Беларусь от 29.10.2014 №6/17 / Электронный ресурс. Режим доступа: http://www.gknt.gov.by/upload/iblock/Post 17 2014.pdf

6. Горизонт 2020. Руководство по грантам. Представление и оценка предложений / Электронный ресурс. Режим доступа: http://www.lp.edu.ua/sites/default/files/book/2016/3368/h2020-guide-pse_en.pdf

7. Гольдштейн, Г.Я. Стратегический инновационный менеджмент. Учебное пособие. / Г.Я. Гольдштейн - Таганрог:

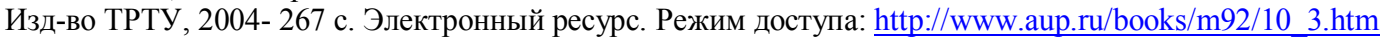

8. Оцінка науково-технічного рівня НДР / Электронный ресурс. Режим доступа: http://www.novaecologia.org/voecos462-1.html

9. Іванілов, І.М. Визначення науково-технічної ефективності результатів наукових досліджень 3 позиції сучасної економетрії / І.М. Іванілов, О.Г. Приймаков, Т.М Сагайдачна // Электронный ресурс. Режим доступа: http://www.khntusg.com.ua/files/sbornik/vestnik_136/st\%209.pdf. 
10. Карпов, В.А. Методика оцінки ефективності науково-дослідних робіт / В.А. Карпов, Т.С. Корольова, А.З.Підгорний - Одеса: ОДЕУ, ротапринт, 2005 р. - 19 с.

11. Самохвалов, Ю.Я. Экспертное оценивание. Методический аспект / Ю.Я. Самохвалов, Е.М. Науменко. - К.:ДУІКТ, 2007. $-262 \mathrm{c}$.

12. Шапарь, В.Б. Новейший психологический словарь / В.Б. Шапарь, В.Е. Рассоха, О.В. Шапарь; под. общ. ред. В.Б. Шапаря. - Изд. 4-е - Роснов н/Д. Феникс, 2009, с. 144.

13. Harrington, E.C. The desirable function // Industrial Quality Control. - 1965. -Vol. 21. No. 10. - pp. 494-498.

14. Пичкалев, А.В. Обобщенная функция желательности Харрингтона для сравнительного анализа технических средств / Исследования наукограда. - 2012. - № 1. - С. 25-28.

15. Ахназарова, С. Л., Гордеев Л. С. Использование функции желательности Харрингтона при решении оптимизационных задач химической технологии: учеб.-мет. пособие / С.Л. Ахназарова, Л.С. Гордеев. - М.: РХТУ им. Д. И. Менделеева, 2003. - 76 c.

Рецензент: д-р техн. наук, проф. К. С. Козелкова, Державний університет телекомунікацій, Київ Received (Надійшла) 20.06.2018

Accepted for publication (Прийнята до друку) 01.08.2018

\title{
Оцінка ефективності наукових і науково-технічних проектів на основі узагальненої функції Харрінгтона
}

\section{Ю. Я. Самохвалов, О. І. Бурба}

Предметом досліджень в статті $є$ процеси оцінки науково-технічного рівня наукових і науково-технічних проектів шляхом застосування бальних шкал різної довжини з використанням в якості опції узагальненого показника адитивної згортки. Метою статті є розробка методичного підходу до оцінки ефективності наукових і науково-технічних проектів, згідно з яким в якості інтегрального показника використовується узагальнена функція Харрінгтона. Завдання статті полягає в аналізі існуючих підходів до оцінки науково-технічного рівня наукових і науково-технічних проектів, методичних аспектів використання узагальненого показника ефективності та обгрунтування використання узагальненої функції Харрінгтона. В ході дослідження використовувалися методи системного та порівняльного аналізу, методи експертного оцінювання, математичного та імітаційного моделювання. Отримані наступні результати. Розглянуто систему критеріїв і показників оцінки, на підставі яких визначається ступінь прогресивності (новизни) i корисності результатів науково-дослідних і дослідно-конструкторських робіт. Оцінка науково-технічного рівня проекту здійснюється експертним шляхом і грунтується на отриманні чисельних значень показників новизни, значущості для науки і практики, об'єктивності, доказовості і точності результатів з подальшим обчисленням інтегрального (узагальненого) показника за конкретним проектом. При цьому запропоновано використання узагальненої функції Харрінгтона, яка дозволяє уникнути використання адитивного інтегрального показника при оцінці науково-технічної якості проектів. Висновки. Розглянуто застосування узагальненої функції Харрінгтона в якості інтегрального показника ефективності наукових і науково-технічних проектів. Це дає можливість, по-перше, уникнути адитивного інтегрального показника якості наукових і науково-технічних проектів По-друге, для кожного показника ефективності вибирати таку шкалу оцінки, максимально узгоджена з об'єктивними відносинами, яким підпорядкований відповідний показник. По-третє, використання шкали Харрінгтона дозволяє інтерпретувати узагальнений показник ефективності наукових дослідження модальними категоріями терміна "бажано".

Ключов і слов а: науково-технічна експертиза, ефективність науково-технічних проектів, узагальнена функція Харрінгтона, шкала оцінювання.

\section{Assessment of the efficiency of scientific and scientific and technical projects based on the Harrington generalized function}

\author{
Yu. Samokhvalov, O. Burba
}

The subject of research in the article are the processes of assessing the scientific and technical level of scientific and technical projects by applying ball scales of various lengths, using as a function the generalized index of additive convolution. The goal of the article is to develop a methodical approach to assessing the effectiveness of scientific and technical projects, according to which the generalized Harrington function is used as an integral indicator. The task of the article is to analyze the existing approaches to the evaluation of the scientific and technical level of scientific and technical projects, the methodological aspects of using the generalized efficiency index and the rationale for using the generalized Harrington function. During the research methods of system and comparative analysis, methods of expert evaluation, mathematical and simulation modeling were used. The following results are obtained. The system of evaluation criteria and indicators is considered, on the basis of which the degree of progressiveness (novelty) and utility of the results of research and development work is determined. The evaluation of the scientific and technical level of the project is carried out expertly and is based on obtaining numerical values of novelty indicators, significance for science and practice, objectivity, evidence and accuracy of results with subsequent calculation of the integral (generalized) indicator for a specific project. In this case, the use of Harrington's generalized function is suggested, which avoids the use of an additive integral index in assessing the scientific and technical quality of projects. Conclusions. The application of Harrington's generalized function as an integral indicator of the effectiveness of scientific and scientific and technical projects is considered. This makes it possible, first, to avoid the additive integral indicator of the quality of scientific and technical projects. Secondly, for each efficiency index, to choose such a scale of assessment, is maximally consistent with the objective relations to which the corresponding indicator is subordinate. Thirdly, the use of the Harrington scale makes it possible to interpret the general indicator of the effectiveness of scientific research by modal categories of the term "desirable".

Keywords: scientific and technical expertise, efficiency of scientific and technical projects, generalized Harrington function, scale of evaluation. 